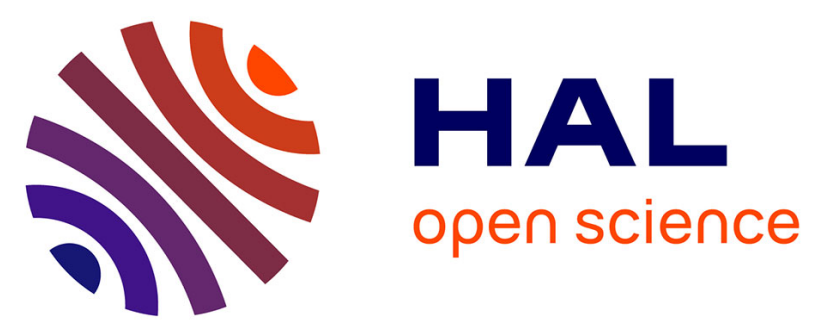

\title{
Surgical technique for the implantation of mechanical circulatory support with the Impella 5.0 pump in a patient with post-cardiotomy cardiogenic shock
}

Hamed Al Kalbani, Charles Juvin, Guillaume Lebreton

\section{- To cite this version:}

Hamed Al Kalbani, Charles Juvin, Guillaume Lebreton. Surgical technique for the implantation of mechanical circulatory support with the Impella 5.0 pump in a patient with post-cardiotomy cardiogenic shock. Annals of Cardiothoracic Surgery, 2021, 10 (2), pp.292 - 294. 10.21037/acs-2020-cfmcs-33 . hal-03197952

\section{HAL Id: hal-03197952 \\ https://hal.sorbonne-universite.fr/hal-03197952}

Submitted on 14 Apr 2021

HAL is a multi-disciplinary open access archive for the deposit and dissemination of scientific research documents, whether they are published or not. The documents may come from teaching and research institutions in France or abroad, or from public or private research centers.
L'archive ouverte pluridisciplinaire HAL, est destinée au dépôt et à la diffusion de documents scientifiques de niveau recherche, publiés ou non, émanant des établissements d'enseignement et de recherche français ou étrangers, des laboratoires publics ou privés. 


\title{
Surgical technique for the implantation of mechanical circulatory support with the Impella 5.0 pump in a patient with post- cardiotomy cardiogenic shock
}

\author{
Hamed Al Kalbani ${ }^{1}$, Charles Juvin ${ }^{1}$, Guillaume Lebreton ${ }^{1,2}$ \\ ${ }^{1}$ Department of Cardio-Vascular Surgery, Cardiac Institution, La Pitié-Salpêtrière Hospital, Sorbonne University, Paris, France; ${ }^{2}$ Institute of \\ CArdiometbolism \& Nutrition (ICAN), UMRS 1166, Sorbonne University, Paris, France \\ Correspondence to: Guillaume Lebreton. Department of Cardio-Thoracic Surgery, Pitié-Salpétrière Hospital, Paris, France. \\ Email: guillaume.lebreton@aphp.fr.
}

Submitted Jan 14, 2021. Accepted for publication Mar 02, 2021.

doi: 10.21037/acs-2020-cfmcs-33

View this article at: http://dx.doi.org/10.21037/acs-2020-cfmcs-33

\section{Clinical vignette}

A fifty-one-year-old male with no significant medical history, presented with acute severe shortness of breath. Emergency echocardiogram revealed dilated cardiomyopathy and severe left ventricular dysfunction with an ejection fraction (EF) of $25-30 \%$, and severe mitral regurgitation due to $\mathrm{P} 2$ cusp prolapse and ruptured chordae tendineae.

Given the patients' cardiogenic shock with severe refractory hypoxemia, veno-arterial extracorporeal membrane oxygenation (VA-ECMO) was implanted and inotrope support commenced. The patient underwent mitral valve repair and implantation of mechanical circulatory support Impella 5.0 pump (Abiomed, Danvers, MA, USA), for post-cardiotomy cardiogenic shock (PCCS).

The Impella was explanted on the ninth postoperative day. The patient stayed in the intensive care unit for 11 days, including 3 days after explantation, and was discharged home 14 days post-explant and 23 days postoperatively with an EF of $35-40 \%$.

\section{Surgical techniques}

Before the procedure, a computed tomography (CT) scan or ultrasound imaging of the axillary artery is important to ensure the artery has a minimum caliber of $6.20 \mathrm{~mm}$, which is necessary for the Impella 5.0 device's implantation (if $<6.20 \mathrm{~mm}$, Impella CP can be used). The procedure can be performed in a regular operating room, however a hybrid operating room is preferred.

General anesthesia is induced. The patient is placed in supine positioning and a transesophageal echocardiography (TEE) probe introduced. A rolled sheet is placed under the left shoulder to properly expose the incision site.

A small transverse 5-7 centimeters skin incision is made approximately 2 centimeters inferior and parallel to the left clavicle. The clavipectoral fascia is opened. The pectoralis major muscle is split and retracted by a retractor.

Small vessel branches are clipped or ligated. Once the axillary artery is visualized, it is dissected and looped by two retraction tapes in order to facilitate its exposure. The patient is then heparinized for an activated clotting time (ACT) $>250$ seconds. The axillary artery is clamped with a vascular clamp and a longitudinal $15 \mathrm{~mm}$ incision is made. End-to-side anastomosis with an $8 \mathrm{~mm}$ Dacron graft is made using a running 6-0 prolene suture. After hemostasis is achieved, the graft is clamped and tunneled subcutaneously through a small incision 10 to 15 centimeters (to reduce the infectious risk) below the subclavian approach.

The Impella introducer kit is introduced on the distal part of the graft and secured with the graft lock. Using both TEE and fluoroscopy, a soft 0.035 -inch guidewire is introduced and advanced into the left ventricle (LV). This guidewire is then exchanged with a 0.018-inch Impella guidewire using a pigtail catheter. Alternatively, the guidewire can be inserted in the LV before cross-clamping. Cross-clamping is then performed while the guide wire is left in situ to facilitate subsequent insertion of the Impella.

The Impella is then introduced and placed in the 
transaortic valve position over the guidewire, under the control of both fluoroscopy and TEE, along with the positioning signal on the Impella monitor. The device is activated after removing the guidewire. The trimmed graft is secured around the catheter using a heavy silk tie and the two skin incisions are classically closed.

\section{Comments}

Why we recommend Impella over VA-ECMO for postcardiotomy cardiogenic shock

PCCS occurs in $0.2-6 \%$ of patients undergoing coronary or valvular surgeries and is associated with high mortality rates of $50-80 \%$ (1). Over the last 50 years, VA-ECMO has been used to support patients with PCCS (2); however, from our experience, we recommend the use of Impella 5.0 over the use of VA-ECMO. VA-ECMO is not only invasive, but also associated with significant morbidity and poor quality of life (3). Impella 5.0 has proven itself an effective minimally invasive treatment option for critically ill patients with PCCS and is associated with favorable survival outcomes. Our department published a study in 2020 in which Impella was used to support 29 patients with PCCS. Of those 29, Impella was successfully weaned in $72.4 \%$, and $58.6 \%$ survived to discharge, with $58.6 \%$ survival at 30 -day and $51.7 \%$, survival at 1 -year (4).

Furthermore, Impella 5.0 was associated with recovery of native heart function in $100 \%$ of patients who survived to discharge because it provides effective hemodynamic support by achieving both LV unloading and systemic perfusion (3). This is in contrast to ECMO, which improves systemic perfusion without directly unloading the LV (5). The retrograde flow generated by VA-ECMO in the descending aorta, increases the afterload, thus resulting in $\mathrm{LV}$ distension and further impairing heart recovery. Furthermore, Impella 5.0 aids in transitioning off cardiopulmonary bypass $(\mathrm{CPB})$, given the beneficial effect on hemodynamics (4).

In addition, while implantation of VA-ECMO via femoral cannulation often restricts mobility (6), axillary implantation of the Impella 5.0 allows early mobilization which contributes to improved survival outcomes (6).

\section{Technical points during the implantation of Impella 5.0?}

There are three key technical points that must be highlighted. First, the positioning of the Impella must be properly placed in the transaortic valve position under the control of both fluoroscopy and TEE, along with the positioning signal on the Impella monitor.

Second, proper hemostasis must be achieved because of both ECMO-associated coagulopathy and the need for post-operative anticoagulation.

Third, during the weaning of $\mathrm{CPB}$ and transition to Impella, it is crucial to balance the flow support between the two. In order to manage this transition effectively, mechanical ventilation must be restarted, followed by a gradual decrease in CPB flow in order to fill the LV, thus providing a smooth change to Impella support.

\section{What are further indications for Impella?}

Although, Impella has often been used for patients with PCCS undergoing coronary or valvular surgeries with low EF $(<25 \%)$, other indications include ventricular septal defect (VSD) and ruptured LV. In these settings, Impella support can provide improved catheterization and recovery of native heart function.

\section{Which axillary artery for Impella implantation?}

We recommend the use of the left axillary artery over the right axillary artery for Impella implantation for two main reasons. First, the shape and presentation of the device make it easier to direct and place in the transaortic position. Second, to avoid injury to the right carotid artery especially when removing the device.

\section{Acknowledgments}

Funding: None.

\section{Footnote}

Conflicts of Interest: GL received research grants and honoraria for lectures from Abiomed. The other authors have no conflicts of interest to declare.

Open Access Statement: This is an Open Access article distributed in accordance with the Creative Commons Attribution-NonCommercial-NoDerivs 4.0 International License (CC BY-NC-ND 4.0), which permits the noncommercial replication and distribution of the article with the strict proviso that no changes or edits are made and the 
original work is properly cited (including links to both the formal publication through the relevant DOI and the license). See: https://creativecommons.org/licenses/by-nc-nd/4.0/.

\section{References}

1. Fux T, Holm M, Corbascio M, et al. Venoarterial extracorporeal membrane oxygenation for postcardiotomy shock: risk factors for mortality. J Thorac Cardiovasc Surg 2018;156:1894-902.e3.

2. Doersch KM, Tong CW, Gongora E, et al. Temporary left ventricular assist device through an axillary access is a promising approach to improve outcomes in refractory cardiogenic shock patients. ASAIO J 2015;61:253-8.

3. Khorsandi M, Dougherty S, Bouamra O, et al. Extracorporeal membrane oxygenation for refractory

Cite this article as: Al Kalbani H, Juvin C, Lebreton G. Surgical technique for the implantation of mechanical circulatory support with the Impella 5.0 pump in a patient with post-cardiotomy cardiogenic shock. Ann Cardiothorac Surg 2021;10(2):292-294. doi:10.21037/acs-2020-cfmcs-33 cardiogenic shock after adult cardiac surgery: a systematic review and meta-analysis. J Cardiothorac Surg 2017;12:55.

4. David CH, Quessard A, Mastroianni C, et al. Mechanical circulatory support with the Impella 5.0 and the Impella Left Direct pumps for postcardiotomy cardiogenic shock at La Pitié-Salpêtrière Hospital. Eur J Cardiothorac Surg 2020;57:183-8.

5. Mohite PN, Sabashnikov A, Koch A, et al. Comparison of temporary ventricular assist devices and extracorporeal life support in post-cardiotomy cardiogenic shock. Interact Cardiovasc Thorac Surg 2018;27:863-9.

6. Esposito ML, Jablonski J, Kras A, et al. Maximum level of mobility with axillary deployment of the Impella 5.0 is associated with improved survival. Int J Artif Organs 2018;41:236-9. 